\title{
MINIMAL GRAPHS WITH RESPECT TO GEOMETRIC DISTANCE REALIZABILITY
}

\author{
TOMÁŠ MADARAS \\ AND \\ PAVOL ŠIROCZKI \\ Institute of Mathematics \\ P.J. Šafárik University in Košice \\ Jesenná 5, 04001 Košice, Slovakia \\ e-mail: tomas.madaras@upjs.sk \\ siroczki@gmail.com
}

\begin{abstract}
A graph $G$ is minimal non-unit-distance graph if there is no drawing of $G$ in Euclidean plane having all edges of unit length, but, for each edge $e$ of $G, G-e$ has such a drawing. We prove that, for infinitely many $n$, the number of non-isomorphic $n$-vertex minimal non-unit-distance graphs is at least exponential in $n$.
\end{abstract}

Keywords: unit-distance graph, odd-distance graph, Euclidean plane.

2010 Mathematics Subject Classification: 05C62.

\section{REFERENCES}

[1] N. Alon and A. Kupavskii, Two notions of unit distance graphs, J. Combin. Theory Ser. A 125 (2014) 1-17.

doi:10.1016/j.jcta.2014.02.006

[2] P. Erdős, F. Harary and W.T. Tutte, On the dimension of a graph, Mathematika 12 (1965) 118-122.

doi:10.1112/S0025579300005222

[3] R.L. Graham, B.L. Rotschild and E.G. Strauss, Are there $n+2$ points in $\mathbb{E}^{n}$ with odd integral distances?, Amer. Math. Monthly 81 (1974) 21-25.

doi:10.1080/00029890.1974.11993491 
[4] B. Horvat, J. Kratochvíl and T. Pisanski, On the computational complexity of degenerate unit distance representations of graphs, Lecture Notes in Comput. Sci. 6460 (2011) 274-285.

doi:10.1007/978-3-642-19222-7_28

[5] V.P. Korzhik and B. Mohar, Minimal obstructions for 1-immersions and hardness of 1-planarity testing, J. Graph Theory 72 (2013) 30-71. doi:10.1002/jgt.21630

[6] K. Kuratowski, Sur le problème des courbes gauches en topologie, Fund. Math. 15 (1930) 271-283.

doi:10.4064/fm-15-1-271-283

[7] L. Piepmeyer, The maximum number of odd integral distances between points in the plane, Discrete Comput. Geom. 16 (1996) 113-115. doi:10.1007/BF02711135

[8] M. Rosenfeld and N.L. Tiên, Forbidden subgraphs of the odd-distance graph, J. Graph Theory 75 (2014) 323-330. doi:10.1002/jgt.21738

[9] A. Soifer, The Mathematical Coloring Book (Springer-Verlag, New York, 2009). doi:10.1007/978-0-387-74642-5

[10] M. Tikhomirov, On computational complexity of length embeddability of graphs, Discrete Math. 339 (2016) 2605-2612. doi:10.1016/j.disc.2016.05.011

[11] D.B. West, Introduction to Graph Theory (Prentice Hall, 1996).

[12] H. Weyl, Über die Gibbs'sche Erscheinung und verwandte Konvergenzphänomene, Rend. Circ. Mat. 30 (1910) 377-407.

doi:10.1007/BF03014883

Received 9 April 2018

Revised 6 August 2018

Accepted 6 August 2018 